\title{
Relationship of Mathematics Olympiad Performance of Gifted Students with IQ and Mathematics Achievement
}

\author{
Ali İhsan BORAN ${ }^{*}$ Kübra AÇIKGÜL ${ }^{* *}$ Mustafa Serdar KÖKSAL ${ }^{* * *}$
}

Received: 19 March 2014

Accepted: 12 March 2015

\begin{abstract}
The purpose of this study is to investigate relationship of mathematics Olympiad (analysis-algebra and geometry) scores of gifted students with IQ scores (verbal, performance and general) and mathematics achievement scores of the gifted students. Study group of the study included 64 gifted students (27 girls and 37 boys) who took courses from one Science and Art Center. Data of study involved scores of the participants on mathematics Olympiad exam, WISC-R test and school mathematics achievement. For analysis of the data Pearson correlation analysis, Spearman correlation analysis, independent groups' t-test and Mann Whitney U test were utilized. The findings showed that there was no significant relationship between the Olympiad scores on analysis-algebra and geometry and IQ scores (general, performance and verbal). But the Olympiad scores on analysis-algebra and geometry factors were significantly related to school mathematics achievement. Comparing IQ scores of highest and lowest scorer groups on the Olympiad scores showed that there were no significant differences between IQ scores (general, performance and verbal) of the groups. However school mathematics scores of the participants significantly differed in terms of groups determined based on analysis-algebra and geometry scores.
\end{abstract}

Keywords: Gifted student, giftedness, identifying giftedness, math olympiad, achievement in mathematics.

\section{Extended Abstract}

Purpose and Significance: Identification of gifted students has importance due to their potential in contributing to the society's development. But deification of them is a hard task. Nowadays IQ tests are popular in identification and selection of gifted students (Akarsu, 2001). In spite of frequent use of IQ tests, there are also drawbacks in using IQ tests in the identification (Porter, 2012). Some researchers suggested using achievement tests and Olympiad scores in identification of gifted students (Konold \& Canivez, 2010; Jeltova \& Grigorenko, 2005; Lohman, 2012). Hence, there is a need to determine place of using these types of identification ways.

This study investigates possible relationship between mathematics Olympiad scores, IQ scores and school mathematics achievement. By this way, we can see place of mathematics Olympiad scores in identifying gifted students. Identification of gifted students is frequently done by using IQ scores. However multiple evaluation by using different instruments and observation protocols is suggested by different researchers in current literature (Kaufman \& Sternberg, 2008; Lohman, 2012). Use of achievement tests, IQ tests and Olympiad scores are the most preferred ways in identification (Konold \& Canivez, 2010; Jeltova \& Grigorenko, 2005; Lohman, 2012). But Olympiad

\footnotetext{
* Corresponding Author: Ph.D, Science and Arts Center, Malatya, Turkey, aihsan422@gmail.com

*** Res. Assist., Inonu University, Malatya, Turkey, kubra.acikgul@inonu.edu.tr.

**** Assoc. Prof. Dr., Inonu University, Malatya, Turkey, mustafa.koksal@inonu.edu.tr.
} 
scores are not used in for identification in Turkey. Studying on relationships of these three ways on identification can show importance of using Olympiad scores in identification. Since correlation might provide evidence for measuring the same thing. Hence if we can see low or none correlation between IQ scores, mathematics achievement and Olympiad scores, we can speculate that mathematics olympiad scores can be used for identification as additional measurement factor. Therefore the purpose of this study is to investigate relationship of mathematics olympiad scores of gifted students with IQ scores and school mathematics achievement scores. The research questions of the study are

1. Is there any statistically significant relationship between Mathematics Olympiad scores and IQ scores (Performance, Verbal and Total) of the gifted students?

2. Is there any statistically significant relationship between Mathematics Olympiad scores and school mathematics achievement scores of the gifted students?

3. Is there any significant difference between IQ scores of the gifted students in two different groups representing highest $27 \%$ and lowest $27 \%$ of the all students in terms of analysis-algebra scores?

4. Is there any significant difference between IQ scores of the gifted students in two different groups representing highest $27 \%$ and lowest $27 \%$ of the all students in terms of geometry scores?

5. Is there any significant difference between school achievement scores of the gifted students in two different groups representing highest $27 \%$ and lowest $27 \%$ of the all students in terms of analysis-algebra scores?

6. Is there any significant difference between school achievement scores of the gifted students in two different groups representing highest $27 \%$ and lowest $27 \%$ of the all students in terms of geometry scores?

Method: The study included 64 gifted students who were enrolled in courses provided by Science and Art centers. They were conveniently selected. The data were collected by WISC-R test, school mathematics achievement scores and mathematic Olympiad test. Then, the data were analyzed by Pearson correlation analysis, Spearman Correlation analysis, independent $\mathrm{t}$ test and Mann Whitney $\mathrm{U}$ test. To prevent alpha level inflation Bonferroni correction was done. For the assumptions of the tests, skewness and kurtosis values of the scores were investigated and the findings showed that school mathematics achievement scores are not distributed normally while other scores have normal distribution. Based on the normality test results, decisions about using analysis techniques were done. Hence both parametric and non-parametric analysis techniques were used to analyze data of this study.

Results: Findings of the study showed that no significant correlation between IQ scores and mathematics olympiad scores on algebra-analysis and geometry was found. However, there is a significant correlation between mathematics olympiad scores, and school mathematics achievement scores. As another side of the study, comparison of the 
students in lowest $27 \%$ and highest $27 \%$ of all scores on the olympiad test showed that there was no significant difference between the groups in terms of IQ scores. But there is as significant difference in school mathematics achievement scores of the groups in favor of highest $27 \%$ group.

Discussion and Conclusion: Based on the findings of this study it can be said that there is a moderate relationship between the Olympiad scores and mathematics achievement scores and no significant correlation between the olympiad scores and IQ scores. This means that the olympiad scores identify different talent factors from achievement and IQ. Therefore, it should be added into the criteria of being gifted. 


\title{
Üstün Yetenekli Öğrencilerin Matematik Olimpiyatlarındaki Performansları ile IQ ve Matematik Başarıları Arasındaki İlişki
}

\author{
Ali İhsan BORAN* ${ }^{*}$ Kübra AÇIKGÜL ${ }^{* *}$ Mustafa Serdar KÖKSAL ${ }^{* * *}$
}

Makale Gönderme Tarihi: 19 Mart 2014

Makale Kabul Tarihi: 12 Mart 2015

\begin{abstract}
ÖZET: $\mathrm{Bu}$ araştırmanın amacı, üstün yetenekli öğrencilerin matematik olimpiyat puanlarının (analiz-cebir ve geometri puanları), IQ puanları (sözel, performans ve genel puanlar) ve okul matematik başarısı değişkenleri ile ilişkisini araştırmaktır. Araştırmanın çalışma grubu bir Bilim ve Sanat Merkezi'ne kayıtlı 27'si kız, 37'si erkek olmak üzere toplam 64 üstün yetenekli öğrenciden oluşmaktadır. Araştırmada veri olarak, WISC-R puanları, okul matematik puanları ve matematik olimpiyat testi puanları kullanılmıştır. Araştırmanın verileri Pearson korelasyon analizi, Spearman korelasyon analizi, bağımsız gruplar t-testi ve Mann Whitney U testi ile analiz edilmiştir. Elde edilen bulgular, üstün yetenekli öğrencilerin analiz-cebir ve geometri puanları ile genel IQ, sözel ve performans IQ puanları arasında istatistiksel olarak anlamlı bir ilişki olmadığını göstermiştir. Fakat analiz-cebir ve geometri puanlarının okul matematik puanlarıyla anlamlı bir ilişki gösterdiği belirlenmiştir. Analiz-cebir ve geometri puanları açısından üst ve alt grup IQ puanları ve okul matematik başarı puanlarının karşılaştırılması da benzer bir bulgu sunmuştur. Analizcebir ve geometri puanları açısından üst ve alt gruplar arasında genel IQ, sözel ve performans IQ puanları arasında istatistiksel olarak anlamlı bir fark bulunmamıştır. Fakat analiz-cebir ve geometri puanları açısından üst ve alt grupların okul matematik puanları arasında üst grup lehine anlamlı bir fark gözlenmiştir.
\end{abstract}

Anahtar Sözcükler: üstün yetenekli öğrenci, üstün zekâ, üstün yetenekliliği belirleme, matematik olimpiyat1, matematik başarısı.

\section{Giriş}

Üstün yeteneklilik ve üstün yetenekli öğrencilerin eğitimi ülkemizde önemli bir araştırma alanı haline gelmiştir. Üstün yeteneklilerin eğitimi konusunda önemli bir basamak tanılamanın uygun ve çok boyutlu yollarla yapılmasıdır. Ülkemizde tanılama süreci Wechsler Zekâ Testi (WISC-R) kullanımı ağırlıklı bir yolla yapılmaktadır. Her ne kadar WISC-R geçerlik ve güvenirlik açısından veri destekli bir test olsa da ölçmeye odaklandığı özellikler açısından sınırlılıklara sahiptir. Bu sebeple WISC-R yanında alternatif yolların da tanılamada işe koşulması gerekmektedir. Özellikle de performansa dayalı tanılama yollarının da sürece eklenmesi önem arz etmektedir. Matematik olimpiyatları performans firsatı sağlaması açısından üstün yeteneklilerin tanılanmasında önemli bir yere sahiptir. Matematik olimpiyatlarından elde edilen puanlar, okul başarısı ve IQ tanılamayı zenginleştiren üç önemli unsurdur. Fakat her bir unsurun değeri tanılamada ölçtükleri özellikten kaynaklanmaktadır. Ölçülen özelliklerin farklı olması ve bu üç unsurun ilişkisiz ya da kısmen ilişkili olması tanılama sürecine dâhil edilmelerinde önemli bir karar kriteri oluşturmaktadır. Bu sebeple bu çalışmada üstün yetenekli öğrencilerin Matematik Olimpiyat Performans Puanları, IQ puanları ve Okul Başarısı arasındaki ilişki incelenmiştir.

\footnotetext{
* Sorumlu Yazar: Dr., Bilim ve Sanat Merkezi, Malatya, aihsan422@ gmail.com

** Araş. Gör., İnönü Üniversitesi, Malatya, kubra.acikgul@inonu.edu.tr

**** Doç. Dr., İnönü Üniversitesi, Malatya, mustafa.koksal@inonu.edu.tr
} 


\section{Üstün Yeteneklilik}

Ülkemizde üstün yeteneklilik yaşıtlarına oranla belirli bir akademik alanda ya da zekâ, yaratıcılık, sanat ve liderlik değişsenleri açısından daha üst düzeyde performans gösterme olarak tanımlanmaktadır (MEB, 2007). Renzulli ve Reis (1985) üstün yetenekliliği "Ortalamanın üzerinde bir kabiliyet, yaratıcl düşünme ve görev sorumluluğunun toplamı" olarak tanımlamaktadır. Tannenbaum (2003)'e göre üstün yeteneklilik, yeteneklerin sonucu ortaya çıkan performanstır. Üstün yetenekliliğin belirlenmesinde çeşitli kriterler ele alınmaktadır. Literatürde zekâ düzeyi, üstün yetenekliliğin güçlü bir göstergesi olarak ele alınmış ve zekânın katkılarına vurgu yapılmıştır. Zekânın ölçümüne ilişkin psikologlar zekâ ölçümü açısından en popüler ölçümler arasında zekâ testlerini göstermektedirler (Stinnett, Havey ve Oehler-Stinnett, 1994; Wilson ve Reschly, 1996). Daniel (1997), zekâ testlerini; psikometrik-yetenek zekâ testleri, nöropsikolojik zekâ testleri ve dinamik zeka testleri olarak sınıflandırmıştır. Akarsu (2001) psikometrik zekâ testleri içinde özellikle "Wechsler Zekâ Testi (WISC-R ve WISC-III)" versiyonlarının yaygın olarak kullanıldığını ifade etmiştir.

Wechsler'in testinden sözel puan, performans puanı ve genel puan olmak üzere üç tür puan hesaplanmakta olup, genel puan, sözel ve performans puanlarının birleşimini içermektedir (Khalfa, 1994). WISC-R'dan elde edilen puanlar IQ adı verilen bir katsayıya dönüştürülüp tanılama için kullanılmaktadır (Moffitt ve Silva, 1987; Wechsler, 1974). Gross (2000) üstün yetenekliliğin düzeylerini IQ puanlarına göre sınıflandırmıştır. Tablo 1'de Gross'un yaptığı sınıflandırma sunulmuştur.

Tablo 1

Üstün Yetenekliliğin Düzeyleri (Gross, 2000)

\begin{tabular}{lll}
\hline Düzey & Zekâ Bölümü & Yaygınlık Oranı \\
\hline Hafif düzeyde üstün yetenekli & $115-129$ & $1 / 40$ \\
Normal düzeyde üstün yetenekli & $130-144$ & $1 / 40-1 / 1000$ \\
Çok üstün yetenekli & $145-159$ & $1 / 1000-1 / 10000$ \\
Olağan üstün yetenekli & $160-179$ & $1 / 10000-1 / 1$ milyon \\
Dahi seviyesinde üstün yetenekli & $180+$ & $1 / 1$ milyondan daha az \\
\hline
\end{tabular}

Yapılan çalışmalar üstün yetenekliliği tanılamada kullanılan IQ zeka puanlarının öğrencilerin matematik, okuma, yazma, okuduğunu anlama becerileri ve konuşma becerilerini yordadığını göstermiştir (Hulslander, Olson, Willcutt ve Wadsworth, 2010; Konold ve Canivez, 2010). Her ne kadar IQ önemli bileşenleri yordasa da üstün yeteneklilik tanımındaki tüm bileşenlere yönelik bilgi sağlayamamaktadır. Örneğin belirli bir alanda gösterilen yüksek başarıyı tanılama sürecine dahil edememektedir. Benzer şekilde üstün yetenekliliğin belirlenmesinde IQ puanları sıklıkla kullanılmasına karşın Kaufman ve Sternberg (2008), üstün yetenekliliğin yüksek IQ ile aynı olmadığını 
ileri sürmüştür. Ayrıca Porter (2012), Amerika'da üstün yeteneklilerin eğitimi ile ilgili çalışmasında, IQ testi puanlarının güvenilirliği konusunda bazı şüpheler olduğuna dikkat çekmiştir.

Kaufman ve Sternberg (2008), üstün yeteneklileri tanımlamak için kullanılan baskın-genel modeller, baskın-özel modeller, sistem modelleri ve gelişmiş modelleri incelediklerinde üstün yetenekli çocukları tanımlamak için şu üç unsuru dikkate almak gerektiğini vurgulamışlardır.

1. Üstün yeteneklileri belirlemek için çoklu ve çeşitli değerlendirmeler kullanılmalıdır. Çünkü tüm değerlendirme araçların ölçümlerinde hata payı vardır. Çeşitli değerlendirme araçları değiştikçe hata farklılıkları da değişmektedir. Örneğin IQ testleri diğer ölçüm araçlarından daha güvenilir olmalarına rağmen; dar kapsamlıdır.

2. Tanılama, zihinsel kişisel değişkenleri içermelidir. Mesleklerinde ve hayatlarında başarılı olan insanlar için hepsi için akıl temelinde başarmıştır denmesi mümkün değildir. Motivasyon, yaratıcılık, bilgelik, girişim, cesaret, dayanıklılık ve diğer birçok bilinmeyen değişken birey üzerinde bir etkiye sahiptir.

3. Modelin dikkate alındığı kültürel ve sosyalleşme gibi bağlamsal değişkenleri içermelidir.

Özetle belirlemek gerekirse üstün yetenekli çocukları tanımlamak için hiçbir benzersiz doğru yol yoktur, birden fazla yol vardır (Kaufman ve Sternberg, 2008).

$\mathrm{Bu}$ çalışmada çoklu değerlendirme bakış açısıyla okul matematik başarısı, IQ puanları ve matematik olimpiyat puanları dikkate alınarak yapılacak tanılamada birbiri yerine geçebilecek unsurların olup olmadığı ve olimpiyat puanlarının diğer iki unsur ile ilişkisi ele alınmıştır.

\section{Dünyada ve Ülkemizde Üstün Yeteneklileri Tanımlama}

1960'lardan itibaren ABD ve Kanada başta olmak üzere dünyanın çeşitli ülkelerinde üstün yeteneklilerin tanılanması ve eğitimi belirli bir ilerleme kaydetmiştir. $\mathrm{Bu}$ ilerlemeler esnasında her ülke kendilerine özgü üstün yeteneklilikler eğitim sistemleri ve yaklaşımları geliştirmişlerdir, bu gelişimlerle paralel ülkeler arasında çok farklı uygulamalar ortaya çıkmıştır (Akarsu, 2004).

Bir Ortadoğu ülkesi olan İsrail üstün yetenekli çocukların tanılanması ve eğitimlerine önem vermekte, bu alandaki gelişmeler için önemli miktarda kaynaklar ayırmaktadır (Subhi ve Maoz, 2000). Amerika Birleşik Devletleri'nde üstün yeteneklileri kabul eden üç tip okul mevcuttur. A tipi okullarda üstün yeteneklileri tespit için WISC- IV zekâ testi, sınıf öğretmeni ve veli anketleri kullanılır. B tipi okullarda akademik ilerleme testi (The Measures of Academic Progress Test), Otis Lennon Okul Yetenek testi (OLSAT), akıl yapısı (SOI yaratıcılık testi), sınıf öğretmeni ve veli anketleri kullanılır. C tipi okullarda grup veya bireysel yetenek testleri, Stanford başarı testi, alt sınıflar için öğretmen gözlemleri, daha üst sınıflar için veli ve öğretmen anketleri kullanılır (Porter, 2012). Üstün yeteneklilerin belirlenmesi için Almanya'da yaygın olarak kabul edilen model Giriş (Enter) modelidir. Bu modelde tanılamada sadece IQ puanı değil aynı zamanda bireyin gelişim sorunlarını da dikkate almaktadır. 
Giriş modeli; beş etaptan oluşmaktadır. Bunlar; keşfetmek, daraltmak, test etmek, değerlendirmek ve incelemek boyutlarından oluşur. İlk üç adımda çocuk için çeşitli veriler toplanır. Yetenek testlerine ek olarak; aile hayat1, erken gelişim, okul deneyimleri, boş zaman aktiviteleri ve arkadaşlar gibi bilgiler toplanır. İlk üç adımda hedefler daraltılmıştır. Toplanan bilgiler ve test sonuçları, değerlendirme aşamasında kullanılır. İnceleme aşamasında, çocuk sürekli izlenir. Bu aşama sonunda tanılama ve değerlendirme aşamasında yapılan tavsiyelerin uygun olup olmadığ1 ve çocuğun üstünlüğü hakkında karar verilir (Kaufman ve Sternberg, 2008). Assouline ve Lupkowski-Shoplik (2012) üstün yeteneklilerin tanılanmasında kullanılan yetenek arama modelini sunduklarında okul öncesinden lise son sınıfa kadar olan devrede başarı testlerinin kullanımını önermişlerdir. Benzer şekilde Stanley (1990) de önerdiği tanılama sürecinde başarı testlerine yer vermiştir. Daha güncel bir çalışmada Lohman (2012) var olan öğrenme düzeyinden daha üstteki düzeylere hitap eden başarı testlerinin kullanımının üstün yetenekliliği tanılamada etkili olduğunu ifade etmiştir. Rusya'da bu ülkelerden farklı olarak üstün yetenekli gençleri ortaya çıkarmak için olimpiyatlar bir gelenek haline gelmiştir (Jeltova ve Grigorenko, 2005). Yukarıda bahsedilen tanılamaların ortak noktası çoklu değerlendirmeye verdikleri önemdir. Ayrıca Rusya'da dikkate alınan olimpiyat performansının bu değerlendirmede bir yeri olabileceği düşünülmelidir.

Ülkemizde üstün yeteneklilerin belirlenmesinde yapılan çalışmalara gelindiğinde, Bilim ve Sanat Merkezleri’nde üstün yeteneklileri tanımlama işlemleri sırasıyla aday gösterme, grup tarama ve bireysel zekâ testi WISC-R yapılarak belirlenir. Aday gösterme veli, sınıf öğretmeni, rehber öğretmeni, kurullar veya Rehberlik Araştırma Merkezi tarafından yapılmaktadır. $\mathrm{Bu}$ değerlendiriciler gözlem formu kullanarak gözlemledikleri çocuk/öğrencileri aday olarak önerirler. Tamamlanan gözlem formları ve raporlar, özel bir tanılama komisyonunca incelenir. İnceleme sonucunda potansiyele sahip olduğu düşünülen öğrenciler grup taramasına sürecine alınır.

Grup taramasında yeterli performans gösteren çocuk/öğrenciler ile okul öncesi örgün eğitim kurumlarınca veya velisi tarafından aday gösterilen çocuklardan tanılama komisyonunca bireysel incelemeye alınmaları uygun görülenler, üstün yeteneklilerin bireysel incelemesinde kullanılacak objektif ve bağı ölçme araçlarının uygulanmasında rehberlik ve araştırma merkezinde veya diğer örgün eğitim, yaygın eğitim, üniversiteler ile benzeri diğer kurumlarda görevli ve tanılama komisyonunca uygun görülen psikolojik danışmanlarca merkezlerde bireysel incelemeye alınırlar” (MEB, 2007).

Yukarıda izah edildiği gibi ülkemizde yapılan tanılamada performans odaklı bir tanılama unsurunun eksik olduğu, zeka testi ağırlıklı bir tanılamanın odakta olduğu görülmektedir.

\section{Araştırmanın Gerekçesi}

Özetle ülkemizde üstün yetenekliliğin belirlenmesinde IQ testlerinin baskın olduğu görülmektedir. Ancak diğer ülkelerde üstün yeteneklilerin belirlenmesinde 
yapılan çoklu değerlendirmeler ve IQ testlerinin tek başına kullanılmasının bahsedilen sınırlılıkları ülkemizde de çoklu değerlendirme yapılmasının gerekliliğini ortaya çıkarmaktadır. Yukarıda yapılan açıklamaların 1şığında üstün yetenekli bireylerin belirlenmesinde olimpiyat puanlarının kullanılmasının performans üstünde tanılama açısından önemi görülmektedir.

Olimpiyatlar çocukların yaratıcılıklarını ve yeteneklerini göstermelerine müsaade eden çeşitli skolâstik disiplinlerle bağlantılı yarışmalardır (Karp, 2003). Jeltova ve Grigorenko, (2005) öğrenciler üstünlüklerini içeren alanlar ilgili olimpiyatlara katılmaları gerektiğini belirterek olimpiyatların öneminden bahsetmiştir.

Ushakov (2010) yaptığı çalışmada üstün yetenekliliği belirlemede olimpiyat puanlarını ele almıştır. Araştırmacı Rusya'da 800 katılımcıdan elde ettiği verilerin analizi sonucu akıl olimpiyatları sonucu elde edilen puanlar ile (matematik, fen ve beşeri bilimler) zekâ, yaratıcılık ve kişilik testlerinden elde edilen puanlar arasındaki ilişkinin zayıf olduğunu belirlemiştir. Bu durum aynı şeyi ölçmemeye ilişkin bir kanıt sağlamaktadır. Bu sebeple olimpiyat puanları, başarı ve IQ puanlarından ayrı bir kriter olarak ön plana çıkabilir. Ushakov (2010) elde ettiği bulguya dayanarak üstün yetenekliliği belirlemede bir kriter olarak zeka olimpiyatlarını önermiştir.

Yukarıda da ifade edilen duruma bakıldığında tanılamada IQ testleri ve başarı testlerine yer verildiği ama performans gösterme açısından önemli bir firsatı tanımlayan Olimpiyat değerlendirmelerine yeterli önemin verilmediği görülmektedir. Burada Olimpiyat değerlendirmelerinin diğer değerlendirmelerle paralel sonuçlar sağlayacağı fikri yönlendirici olmuş olabilir. $\mathrm{Bu}$ durumun test edilmesi ülkemizde yapılan tanılamalarda Olimpiyat değerlendirmelerinin yerinin ortaya konması açısından önem arz etmektedir.

\section{Araştırmanın Amacı}

$\mathrm{Bu}$ araştırmanın amacı üstün yetenekli öğrencilerin tanılanmasında matematik olimpiyat puanlarının (analiz-cebir, geometri puanları), IQ puanları (sözel, performans ve genel puanlar) ve okul matematik başarısı değişkenleri içindeki yerini araştırmaktır. $\mathrm{Bu}$ araştırma çerçevesinde ele alınan alt problemler şu şekildedir:

1. Katılımcıların matematik olimpiyat puanları IQ puanları (sözel, performans ve genel puanlar) ve okul matematik başarı puanlarıyla istatistiksel olarak anlamlı bir ilişki göstermekte midir?

2. Analiz-cebir puanlarına göre belirlenen $\% 27^{\prime}$ lik alt ve üst grupların IQ puanları arasında ve okul matematik puanları istatistiksel olarak anlamlı bir fark var midir?

3. Geometri puanlarına göre belirlenen \%27'lik alt ve üst grupların IQ puanları ve okul matematik puanları arasında istatistiksel olarak anlamlı bir fark var mıdır?

\section{Yöntem}

$\mathrm{Bu}$ araştırmada ilişkisel araştırma yöntemi kullanılmıştır. Çalışmada üç farklı ölçme yolundan elde edilen veriler arasındaki ilişki ve olimpiyat puanları açısından 
gruplanmış öğrencilerin okul matematik başarısı ve IQ puanı açısından farklılaşıp farklılaşmadığı araştırılmıştır. Araştırmanın verileri Pearson korelasyon analizi, Spearman korelasyon analizi, bağımsız gruplar t testi ve Mann Whitney U testi ile analiz edilmiştir.

\section{Araştırmanın Katılımcıları}

Araştırmaya 64 üstün yetenekli öğrenci (6. Sınıf=23, 7.Sınıf=34, 8.Sınıf=7) katılmıştır. Bu öğrencilerin 27'si kız, 37'si ise erkektir. Katılımcılar bir Bilim ve Sanat Merkezi’nde öğrenim görmekte olan öğrencilerden oluşmaktadır.

\section{Ölçme Araçları}

Ölçme yollarından ilki IQ testi olup, üç alanda (performans, sözel ve genel) öğrencilerin puanları hesaplanmıştır. Araştırmada IQ testi olarak WISC-R dikkate alınmıştır. Bu testin ülkemize uyarlanması Savaşır ve Şahin (1995) tarafından gerçekleştirilmiştir. WISC-R testinin yarılama güvenirliliği, Performans Zekâ Bölümü için 0.93, Sözel Zekâ Bölümü için 0.97 ve Genel Zekâ Bölümü için 0.97 olarak hesaplanmıştır. Alt testler arası ilişkinin, 0.51 ile 0.86 korelasyon değerleri arasında değiştiği görülmüştür (Savaşır ve Şahin; 1995). Bu çalışmada dikkate alınan IQ puanları ilgili Bilim ve Sanat Merkezi (BİLSEM) tarafindan yapılan tanılamada kullanılan IQ puanlarıdır. $\mathrm{Bu}$ sebeple güvenirlik açısından yaşanabilecek olası değişiklikler BİLSEM'lerce dikkate alınan, doğal sürecin içinde olduğundan ihmal edilmiştir ve bu durum çalışmanın "değişmez IQ ölçümü odaklı tanılama" fikrine ilişkin eleştirileri arasındadır. İkinci ölçme yolu okul matematik puanının belirlenmesidir. Burada öğretmen yapımı testlerden öğrencilerin aldıkları puanlar öğretmenleri aracılığıyla elde edilmiştir. Bir diğer veri toplama yolu olarak öğrencilerin katıldıkları matematik olimpiyatları puanlarının iki alan (analiz-cebir, geometri) açısından toplam puanları belirlenmiştir.

Matematik olimpiyat sınavında analiz-cebir alanında 20 ve geometri alanında 10 tane olmak üzere, ilköğretim TÜBİTAK matematik olimpiyat sorularından, Olimpiyat hazırlık kitaplarından, Malatya Bilim ve Sanat Merkezi 2010 BİLMATOL ve 2011 BİLFEMOL sınav sorularından ve kolejlerce yapılan Ulusal Matematik Olimpiyat Sınav Sorularından oluşan 30 soruluk bir test hazırlanmıştır. Testin geçerlik ve güvenirlik çalışmaları ITEMAN programı ile yapılan analizler sonucu elde edilmiştir. Yapılan analiz sonucu madde ayırt edicilik indeksi .20'nin altında olduğu tespit edilen 9 madde testten çıkarılmıştır. Testin güvenirlik katsayısı (KR20) 0.887, güçlük indeksi 0.323 ve ayırt edicilik indeksi 0.779 olarak hesaplanmıştır. Madde bazında incelendiğinde madde güçlüklerinin 0.066-0.816 arasında ve madde ayırt edicilik indeksi 0.413-0.999 arasında değiştiği belirlenmiştir. Ayrıca, testin geneli için hesaplanan madde güçlük indeksi $(\mathrm{p}=0.323)$ testin zor bir test olduğunu göstermektedir. $\mathrm{Bu}$ durum testi oluşturan soruların olimpiyat sınavlarından seçilmiş olmasından kaynaklanmaktadır.

Teste ilişkin soru örnekleri aşağıda sunulmaktadır. 
(Cebir- Analiz Alan Sorusu)

$$
x, y, z \in Z ; x+\frac{1}{y+\frac{1}{z}}=\frac{30}{13} \text { ise } z^{3}-x y=? \begin{array}{llll}
\text { A) } 58 & \text { B) } 64 & \text { C) } 12 & \text { D) } 24
\end{array}
$$

(Cebir- Analiz Alan Sorusu)

Bir malın fiyatında indirim yapıldıktan sonra bir günde satılan mal miktarı $\% 25$ artarken satışlardan elde edilen gelir değişmediğine göre, yüzde kaç indirim yapılmıştır?
A) 20
B) 22,5
C) 25
D) 27,5

(Geometri Alan Sorusu)

Yanda kenar uzunluğu $4 \mathrm{~cm}$ olan $\mathrm{ABCD}$ karesi görülmektedir. [CE] doğru parçası, O merkezli yarım çembere $\mathrm{F}$ noktasında teğettir. Taralı bölgenin alanı kaç santimetrekaredir?
A) $9-2 \Pi$
B) $10-2 \pi$
C) $11-4 \Pi$
D) $12-2 \Pi$

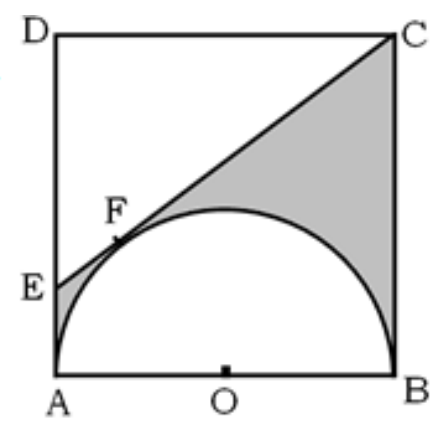

\section{Bulgular}

Verilerin normal dağılım gösterip göstermediklerini belirlemek amacıyla çarpıklık / basıklık değerleri ve histogram grafiği incelenmiştir. Puanların çarpıklık / basıklık katsayılarına ilişkin değerler Tablo 2'de sunulmuştur.

Tablo 2

IQ Puanlarının, Okul Matematik Puanlarının Ve Olimpiyat Puanlarının Çarpıklı/ Basıklık Katsayılarına Ilişkin Değerler

\begin{tabular}{lcccccc}
\hline \multirow{2}{*}{ İstatistikler } & Geometri & $\begin{array}{c}\text { Okul Mat. } \\
\text { Başarısı }\end{array}$ & \begin{tabular}{c} 
IQ Sözel \\
Pualiz- \\
\cline { 2 - 7 } Cebir
\end{tabular} & IQ Performans & $\begin{array}{c}\text { IQ Toplam } \\
\text { Puanı }\end{array}$ & $\begin{array}{c}\text { Puanı } \\
\text { Çarpıklık }\end{array}$ \\
\cline { 2 - 7 } & .83 & .79 & -1.72 & -.03 & -.03 & .80 \\
\hline Basıklık & .58 & .17 & 2.95 & -.67 & -.40 & .37 \\
\hline
\end{tabular}

Tablo 2'de görüldüğ̈̈ gibi okul matematik puanları başarısı hariç diğer puanlara ait çarpıklık ve basıklık değerleri \pm 1 aralığındadır. Bu değişkenlere ilişkin histogram grafikleri bu değişkenlere ait puanların normal dă̆ıldığını göstermektedir. Okul matematik başarısına ait puanların basıklık /çarpıklık değerleri bu puanların normal dağılım göstermediğine işaret etmektedir. Ayrıca histogram grafiği dağılımının dağılımın sola çarpık olduğunu göstermektedir. Normallik testlerinden elde edilen sonuçlara göre IQ sözel, IQ performans ve IQ toplam puanları ile olimpiyat puanları 
(analiz-cebir, geometri) arasındaki ilişki Pearson korelasyon analizi yapılırken okul matematik puanları ile olimpiyat puanları (analiz, cebir, geometri) arasındaki ilişki Spearman korelasyon analizi yapılmıştır. Yapılan Bonferroni düzeltmesi sonucu Pearson korelasyon testi ve bağımsız gruplar t testi için anlamlılık düzeyi $\alpha=0.008$; Spearman korelasyon testi ve Mann Whitney $U$ testi için anlamlılık düzeyi $\alpha=0.025$ olarak belirlenmiştir (Abdi, 2010). Bu farklılık analizlerin doğasının ve amacının farklılığından kaynaklanmaktadır. Her analiz bir bütün olarak el alınmış ve her analizin tekrarları dikkate alınarak alfa ayarlaması yapılmıştır.

Analiz, geometri ve cebir puanlarına göre belirlenen \%27'lik alt ve üst gruplar arasında IQ sözel, IQ performans ve IQ toplam puanları arasında anlamlı bir fark olup olmadığını belirlemek amacıyla bağımsız gruplar için t-testi; okul matematik puanları arasında anlamlı bir fark olup olmadığını belirlemek amacıyla MannWhitney U kullanılmıştır.

Öğrencilerin IQ, Okul Matematik Başarı ve Olimpiyat puanlarına ilişkin tanımlayıcı istatistikler Tablo 3'te verilmiştir.

Tablo 3

Öğrencilerin IQ ve Okul Matematik Başarı Puanları ile Olimpiyat Puanları Arasındaki İlişki

\begin{tabular}{lccccc}
\hline & $N$ & $\overline{\mathrm{x}}$ & Min. Puan & Maks. Puan & ss \\
\hline Analiz-Cebir Puanı & 64 & 31.77 & 5 & 70 & 14.78 \\
Geometri Puanı & 64 & 16.25 & 0 & 50 & 14.42 \\
Okul Matematik Başarısı & 64 & 94.48 & 70 & 100 & 6.58 \\
IQ-Sozel Puanı & 64 & 136.69 & 120 & 156 & 8.64 \\
IQ-Performans Puanı & 64 & 131.19 & 114 & 147 & 7.56 \\
IQ Toplam Puanı & 64 & 137.69 & 130 & 152 & 5.61 \\
\hline
\end{tabular}

Öğrencilerin IQ puanları (IQ Sözel, IQ Performans, IQ Toplam) ile olimpiyat puanları (Analiz-Cebir, Geometri) arasında anlamlı bir ilişki olup olmadığına ilişkin bulgular Tablo 4'de verilmiştir. 
Tablo 4

Öğrencilerin IQ Puanları İle Olimpiyat Puanları Arasındaki İlişki İçin Pearson korelasyon Testi Sonuçları

\begin{tabular}{lccc}
\hline & & Analiz-Cebir & Geometri \\
\hline IQ Sözel Puanı & $r$ & .02 & .09 \\
\hline \multirow{2}{*}{ IQ Performans Puanı } & $p$ & .86 & .46 \\
\hline \multirow{2}{*}{ IQ Toplam Puanı } & $r$ & -.13 & .04 \\
& $p$ & .32 & .70 \\
\hline *p<0.008 (Bonferroni düzeltmesi sonrast) & $r$ & -.08 & -.08 \\
& $p$ & .55 & .54
\end{tabular}

${ }^{*} \mathrm{p}<0.008$ (Bonferroni düzeltmesi sonrasl)

Tablo 4 incelendiğinde öğrencilerin IQ Sözel, IQ performans ve IQ toplam puanları ile Analiz-Cebir ve Geometri puanları arasında anlamlı bir ilişki olmadığ görülmektedir.

Öğrencilerin okul matematik başarı puanları ile olimpiyat puanları (AnalizCebir, Geometri) arasında anlamlı bir ilişki olup olmadığına ilişkin bulgular Tablo 5 'te verilmiştir.

Tablo 5

Öğrencilerin Okul Matematik Başarı Puanları İle Olimpiyat Puanları Arasındaki İlişki İçin Spearman Korelasyon Testi Sonuçları

\begin{tabular}{lccc}
\hline & & Analiz-Cebir & Geometri \\
\hline Okul Matematik Başarısı & $r$ & .500 & .321 \\
& $p$ & $.000^{*}$ & $.010^{*}$ \\
\hline
\end{tabular}

*p<0.025 (Bonferroni düzeltmesi sonrasl)

Tablo 5 incelendiğinde öğrencilerin Okul Matematik Başarı puanları ile Analiz-Cebir puanları arasında orta düzeyde $(\mathrm{r}=.50, \mathrm{p}<.025)$ ve Geometri puanları arasında orta düzeyde $(r=.32, p<.025)$ pozitif yönlü ve anlamlı ilişkiler olduğu belirlenmiştir.

Analiz-Cebir Ve Geometri Puanlarına Göre Belirlenen \%27'lik Alt Ve Üst Grupların IQ Ve Matematik Okul Başarısı Puanları Arasındaki Fark

Analiz puanlarına göre belirlenen \%27'lik alt ve üst grupların IQ puanları arasındaki farka ilişkin yapılan bağımsız gruplar $\mathrm{t}$ testi sonucu elde edilen bulgular Tablo 6'de sunulmuştur. 
Tablo 6

Analiz-Cebir Puanlarına Göre Belirlenen \%27’lik Alt Ve Üst Grupların IQ Puanları Arasındaki Farka İlişkin Bulgular

\begin{tabular}{|c|c|c|c|c|c|c|c|c|}
\hline \multirow{2}{*}{ Değişkenler } & \multirow{2}{*}{$\begin{array}{c}N \\
(n 1=17) \\
(n 2=17)\end{array}$} & \multicolumn{2}{|c|}{$\overline{\mathrm{x}}$} & \multicolumn{2}{|c|}{ ss } & \multirow{2}{*}{$s d$} & \multirow{2}{*}{$t$} & \multirow{2}{*}{$p$} \\
\hline & & $\begin{array}{l}\% 27^{\prime} \text { lik } \\
\text { Alt Grup }\end{array}$ & $\begin{array}{l}\text { \%27’lik } \\
\text { Üst Grup }\end{array}$ & $\begin{array}{l}\% 27^{\prime} \text { lik } \\
\text { Alt Grup }\end{array}$ & $\begin{array}{l}\% 27^{\prime} \text { lik } \\
\text { Üst Grup }\end{array}$ & & & \\
\hline IQ Sözel & 34 & 136.58 & 137.64 & 7.43 & 8.94 & 32 & 0.37 & .71 \\
\hline IQ Performans & 34 & 130.17 & 128.58 & 7.64 & 5.99 & 32 & 0.67 & .50 \\
\hline IQ Toplam & 34 & 137.06 & 136.58 & 5.76 & 5.14 & 32 & 0.25 & .80 \\
\hline
\end{tabular}

*p<0.008 (Bonferroni düzeltmesi sonrası)

Tablo 6 incelendiğinde alt ve üst grupta yer alan öğrencilerin IQ Sözel, IQ Performans ve IQ toplam puanları arasında istatistiksel olarak anlamlı düzeyde farklılaşma olmadığı görülmektedir. Ortalamalar incelendiğinde IQ Sözel için üst grubun ortalaması daha yüksekken IQ performans ve IQ Toplam puanları için alt grubun ortalamasının daha yüksek olduğu belirlenmiştir. Analiz puanlarına göre belirlenen \%27'lik alt ve üst grupların Matematik Okul Başarı puanları arasındaki farka ilişkin yapılan Mann Whitney $U$ testi sonucu elde edilen bulgular Tablo 7'de sunulmuştur.

Tablo 7

Analiz-Cebir Puanlarına Göre Belirlenen \%27'lik Alt Ve Üst Grupların Okul Matematik Başarısı Puanları Arasındaki Farka Ilişkin Bulgular

\begin{tabular}{lcccc}
\hline & $\begin{array}{c}\text { Siralar } \\
\text { Ortalaması }\end{array}$ & $\begin{array}{c}\text { Siralar } \\
\text { Toplamı }\end{array}$ & Mann Whitney U & $p$ \\
\hline Okul Matematik Başarısı & 11.35 & 193.00 & \multirow{2}{*}{40.00} & $.000^{*}$
\end{tabular}

$\mathrm{p}<0.025$

Tablo 7 incelendiğinde alt ve üst grupta yer alan öğrencilerin Okul Matematik Başarı puanlarının istatistiksel olarak anlamlı düzeyde farklılaştı̆̆ı görülmektedir $(\mathrm{p}<.025)$. Geometri puanlarına göre belirlenen \%27'lik alt ve üst grupların IQ puanları arasındaki farka ilişkin yapılan bağımsız gruplar t testi sonucu elde edilen bulgular Tablo 8'de sunulmuştur. 
Tablo 8

Geometri Puanlarına Göre Belirlenen \%27’lik Alt Ve Üst Grupların IQ Puanlart Arasındaki Farka İlişkin Bulgular

\begin{tabular}{|c|c|c|c|c|c|c|c|c|}
\hline \multirow{2}{*}{ Değişkenler } & \multirow{2}{*}{$\begin{array}{c}N \\
(n 1=17) \\
(n 2=17)\end{array}$} & \multicolumn{2}{|c|}{$\overline{\mathrm{x}}$} & \multicolumn{2}{|c|}{ ss } & \multirow{2}{*}{$s d$} & \multirow{2}{*}{$t$} & \multirow{2}{*}{$p$} \\
\hline & & $\begin{array}{l}\% 27^{\prime} \text { lik } \\
\text { Alt Grup }\end{array}$ & $\begin{array}{l}\text { \%27’lik } \\
\text { Üst Grup }\end{array}$ & $\begin{array}{l}\% 27^{\prime} \text { lik } \\
\text { Alt Grup }\end{array}$ & $\begin{array}{l}\% 27^{\prime} \text { lik } \\
\text { Üst Grup }\end{array}$ & & & \\
\hline IQ Sözel & 34 & 138.52 & 136.64 & 8.85 & 9.86 & 32 & 0.58 & .56 \\
\hline IQ Performans & 34 & 130.82 & 130.29 & 8.34 & 5.82 & 32 & 0.21 & .83 \\
\hline IQ Toplam & 34 & 138.94 & 137.00 & 6.92 & 5.71 & 32 & 0.89 & .38 \\
\hline
\end{tabular}

*p<0.008 (Bonferroni düzeltmesi sonrası)

Tablo 8 incelendiğinde alt ve üst grupta yer alan öğrencilerin IQ Sözel, IQ Performans ve IQ toplam puanları arasında istatistiksel olarak anlamlı düzeyde farklılaşma olmadığı görülmektedir. Ortalamalar incelendiğinde IQ Sözel, IQ performans ve IQ Toplam puanları için alt grubun ortalamasının daha yüksek olduğu belirlenmiştir. Geometri puanlarına göre belirlenen \%27'lik alt ve üst grupların Matematik Okul Başarı puanları arasındaki farka ilişkin yapılan Mann Whitney U testi sonucu elde edilen bulgular Tablo 9'da sunulmuştur.

Tablo 9

Geometri Puanlarına Göre Belirlenen \%27'lik Alt Ve Üst Grupların Okul Matematik Başarısı Puanları Arasındaki Farka Ilişkin Bulgular

\begin{tabular}{lcccc}
\hline & $\begin{array}{c}\text { Siralar } \\
\text { Ortalaması }\end{array}$ & $\begin{array}{c}\text { Siralar } \\
\text { Toplamı }\end{array}$ & Mann Whitney U & $p$ \\
\hline Okul Matematik Başarısı & 12.76 & 217.00 & 64.00 & $.005^{*}$ \\
\hline
\end{tabular}

$\overline{\mathrm{p}<0.025}$

Tablo 9 incelendiğinde alt ve üst grupta yer alan öğrencilerin Okul Matematik Başarı puanlarının istatistiksel olarak anlamlı düzeyde farklılaştığı görülmektedir $(\mathrm{p}<.025)$.

\section{Sonuç ve Tartışma}

Çalışmadan elde edilen bulgular IQ puan türleri ve matematik olimpiyat puanları arasında istatistiksel olarak anlamlı bir ilişki olmadığını göstermektedir. Bunun yanında analiz-cebir ve geometri konularındaki olimpiyat puanları, okul matematik başarı puanlarıyla anlamlı bir ilişki göstermektedir. Olimpiyat puanları açısından alt ve üst grup olarak ayrılmış öğrencilerin daha detaylı incelenmesi, gruplar arasında IQ puan türleri açısından anlamlı bir farkın olmadığını, analiz-cebir ve geometri puanları 
açısından üst ve alt grupların okul matematik puanları arasında üst grup lehine anlamlı bir farkın olduğunu göstermiştir. Bu bulgular matematik olimpiyat puanlarının ayrı bir değerlendirme unsuru olduğunu matematik okul başarısı ve IQ puanları yanında üstün yetenekliliğin tanılanmasında yardımcı bir unsur olarak kullanılabileceği fikrini desteklemektedir.

$\mathrm{Bu}$ çalışmada tespit edilen farklılıklar değerlendirme araçlarının içerik farklılığıyla ilgili olabilir. Çünkü IQ testi, sözcük dağarcığı, aritmetik, benzerlikler, yargılama ve sayı dizisi alt testlerini; performans zeka bölümü resim düzenleme, resim tamamlama, parça birleştirme, küplerle desen, şifre ve labirent alt testlerini içermektedir (Öner, 1997). Aynı zamanda yüksek IQ puanına sahip olmak, bireyin gelecek başarı ve başarısızlıklarını şimdiden ortaya koyabilecek tek kriter değildir (Niederer ve Irwin, 2001). Bununla beraber okul matematik başarı testleri, matematik programı içerisindeki konulara odaklı çoktan seçmeli testleri içermektedir. Olimpiyat soruları ise üst düzey matematik konularıyla ilgili içerik sorularını içermektedir. Aslında bu üç değerlendirme üstün yetenekliliğin, genel kabiliyet (IQ), içerik bilgisi (okul başarısı) ve üst düzey performans (Olimpiyat başarısı) boyutlarını yansıtmaktadır (Marland, 1972). Bu bulguları destekleyecek şekilde birçok araştırmacı üstün yeteneklileri tanılama sürecinde tek yönlü bir uygulamadan daha fazlasının yapılması gerektiğini belirtmektedirler. (Johnsen, 2004; Wortham, 2005). Bu çalışmada ele alınan üç yolun, üstün yetenekliliği açıklamakta odaklanılan varyansın belirli bir bölümünü açıkladığı söylenebilir. Elbette tanılamada bu üç yoldan daha fazlasına ihtiyaç duyulmaktadır. Özellikle de öğretmen/veli değerlendirmesi, yaratıcı problem çözme ve sosyal alanlarda yeterlilik düzeyi belirleme gibi yollara da ihtiyaç duyulmaktadır (Ford ve Grantham, 2003; Kim, Cho ve Ahn, 2003; McBee, McCoach, Peters ve Matthews, 2012).

Literatürde üstün yetenekliliğin matematik alanına özgü değerlendirmesinde çeşitli yaklaşımlar kullanılmıştır. Kim, Cho ve Ahn (2003) üstün yeteneklilerin tanılanmasında kullanılmak üzere yaratıcı matematik problemleri çözme kabiliyet testini geliştirmişlerdir. Niederer, Irwin, Irwin ve Reilly (2003) Gelişimsel Matematik Başarı testi ve Problem Çözme Testini matematiksel üstün yetenekliliği tanılamada kullanmışlardır. Bu çalışmalarda ele tercih edilen yolların bu çalışmada önerilen yollarla beraber tanılamada kullanılması üstün yetenekliliğin hem belirli bir alana özgü kısmını hem de genel kabiliyet kısmını tanılamakta kolaylık sağlayacaktır.

$\mathrm{Bu}$ çalışmada önerilen olimpiyat performansının da tanılamada kullanılması süreç ve ürün odaklı tanılamaya katkı sağlayabilir. Bu çalışmada bir tanılama yolu olarak önerilmesine rağmen genelde olimpiyatlar tanılama dışında üstün yeteneklilerin eğitimi için kullanılmıştır (Diezmann, 2005; Ngoi ve Vondracek, 2004; Reichel, 1997). Olimpiyat performansının eğitim dışında tanılama amaçlı ele alınması eğitim sürecinde kullanılmasına da katkı sağlayabilir.

$\mathrm{Bu}$ çalışmada ele alınan problem durumu, özellikle de alan odaklı üstün yetenekliliğin tanılanması üzerine çalışan uzmanlara fikir verebilir. Ayrıca süreç ve ürün odaklı tanılama konusunda tasarım yapmada olimpiyatların nasıl kullanılacağına 
ilişkin fikir de sağlayabilir. Bu çalışmadan elde edilen bulgular olimpiyat puanlarıyla diğer hangi değerlendirme yollarının kullanılabileceğine ilişkin fikir sağlayabilir.

Her ne kadar bu çalışmada önemli bulgular elde edilse de çalışma grubunun 64 kişiyle sınırlı olması, değerlendirmelerde sadece performans ve biliş odaklı yolların kullanılması araştırmanın genellenebilirliğini azaltmaktadır. Ayrıca okul matematik puanları ve olimpiyat puanlarının geçerlik güvenirlikleri ile ilgili kanıt sağlanamaması da bu çalışmanın bulgularını sınırlamaktadır. Gelecek çalışmalarda bu hususlara dikkat edilmesi önerilir. 


\section{Kaynakça}

Abdi, H. (2010). Holm's sequential bonferroni procedure, In N. Salkind (Ed.) Encyclopedia of research design (pp. 574-578). Thousand Oaks, CA: SAGE Publications. Inc.

Akarsu, F. (2001). Üstün yetenekli çocuklar, aileler ve sorunlart. Ankara: Eduser Yayınları.

Akarsu, F. (2004). Üstün yetenekliler. I. Türkiye Üstün Yetenekli Çocuklar Kongresinde sunulmuş sözlü bildiri, 23-25 Eylül, Marmara Üniversitesi, İstanbul.

Assouline, S. G., \& Lupkowski-Shoplik, A. E. (2012). The talent search model of gifted identification. Journal of Psychoeducational Assessment, 30(1), 45-59. Doi: $10.1177 / 0734282911433946$.

Daniel, M.H. (1997). Intelligence testing: Status and trends. American Psychologist, 52(10), 1038-1045.

Diezmann, C. M. (2005) Challenging mathematically gifted primary students. Australasian Journal of Gifted Education, 14(1), 50-57.

Ford, D. Y., \& Grantham, T. C. (2003). Providing access for gifted culturally diverse students: From deficit thinking to dynamic thinking. Theory into Practice, 42(3), $217-225$.

Gross, M.U.M. (2000). Issues in the cognitive development of exceptionally and profoundly gifted individuals. In K. A. Heller, F. J. Monks, R. J. Sternbergand R. F. Subotnik (Eds.), International Handbook of Giftedness and Talent (2nd Edition) (pp. 179-192). Oxford: Pergamon.

Hulslander, J., Olson R.K., Willcutt E.G., \& Wadsworth S.J. (2010). Longitudinal stability of reading-related skills and their prediction of reading development. Scientific Studies of Reading, 14(2), 111-136.

Jeltova, I., \& Grigorenko, E. L. (2005). Systemic approaches to giftedness: Contributions of Russian psychology. In R. J. Sternberg \& J. E. Davidson (Eds.), Conceptions of giftedness (pp. 171-186). New York: Cambridge University Press.

Johnsen, S. K. (2004). Making decisions about placement. In S. K. Johnsen (Ed.), Identifying gifted students: A practical guide (pp. 107-131). Waco, TX: Prufrock Press.

Karp, A. (2003). Thirty years after: The lives of former winners of Mathematical Olympiads. Roeper Review, 25, 83-92.

Kaufman, S.B. \& Sternberg R.J. (2008) Handbook of giftedness in children psycho educational theory, research and best practices. Steven I. Pfeiffer (Ed.), (p.71-91) Florida State University, Tallahassee, USA.

Khalfa, J. (1994). What is intelligence? Cambridge: Cambridge University Press.

Kim, H., Cho, S., \&Ahn, D. (2003). Development of mathematical creative problem solving ability test for identification of gifted in math. Gifted Education International, 18, 164-174. 
Konold, T.R., \& Canivez G.L. (2010). Differential relationships between WISC-IV and WIAT-II scales: an evaluation of potentially moderating child demographics. Educational and Psychological Measurement, 70(4), 613-627.

Lohman, D. F. (in press). Nontraditional uses of traditional measures. In C. M. Callahan \& H. Hertberg-Davis (Eds.), Fundamentals of gifted education. New York, NY: Routledge.

Marland, S. P. (1972). Education of the gifted and talented, Vol. 1. Report to the Congress of the United States by US Commissioner of Education. Washington, DC: US Government Printing Office.

McBee, M. T., McCoach, D. B., Peters, S. J., \& Matthews, M. S. (2012). The case for a schism: A commentary on Subotnik, Olszewski-Kubiliusand Worrel (2011). Gifted Child Quarterly, 56(4), 210-214.

MEB (2007). Bilim ve sanat merkezi yönergesi, http://mevzuat.meb.gov.tr/html/ 2593 0.html adresinden 30.02.2014 tarihinde erişilmiştir..

Moffitt, T.E. \& Silva, P.A.(1987). WISC-R verbal and performance IQ discrepancy in an unselected cohort: clinical significance and longitudinal stability. Journal of Consulting and Clinical Psychology, 55, 768-774.

Ngoi, M.,\&Vondracek, M. (2004). Working with gifted science students in a public high school environment: One school's approach. The Journal of Secondary Gifted Education, 15(4), 141-147.

Niederer, K., \& Irwin, K. C. (2001). Using problem solving to identify mathematically gifted children. Paper presented at the proceedings of the 25th conference of the International Group for the Psychology of Mathematics Education, Utrecht, the Netherlands.

Niederer, K., Irwin, R.J., Irwin, K. C., \& Reilly, I. L. (2003). Identification of mathematically gifted students in New Zealand. High Ability Studies, 14(1), 71-84.

Öner, N. (1997). Türkiye'de kullanılan psikolojik testler. Bir başvuru kaynă̆ı (3.Baskı). İstanbul: Boğaziçi Üniversitesi Yayınları.

Porter, N. (2012). Gifted education in the United States. Child Research Net. Retrieved from http://www.childresearch.net/projects/special/2012_01.html adresinden 30.02.2014 tarihinde indirilmiştir.

Renzulli, J.S. \& Reis, S.M. (1985). The school wide enrichment model: A comprehensive plan for educational excellence, Mansfield Center, CT: Creative Learning Press.

Reichel, H. (1997). Identifying and promoting mathematically gifted pupils and students (12-20 years). High Ability Studies, 8(2), 223-232. doi:10.1080/ 1359813970080207.

Savaşır, I \&Şahin, N. (1995). Wechsler çocuklar için zeka ölçeği (WISC-R) el kitabı. Ankara: Türk Psikologlar Derneği Yayınları, 13-52. 
Stanley, J. C. (1990). Leta Holling worth's contributions to above-level testing of the gifted. Roeper Review, 12, 166-171.

Subhi T. ve Maoz, N. (2000). Middle-East region: efforts, policies, programs and issues. kurt heller (Eds.). International Handbook of Giftedness and Talent. (743-757). Oxford: Elsevier Science Ltd.

Stinnett, T.A., Havey, J.M. \& Oehler-Stinnett, J. (1994). Current test usage by practicing school psychologists: A national survey. Journal of Psycho Educational Assessment, 12, 331-350.

Tannenbaum, A.J. (2003). Nature and nurture of giftedness. In N. Colangelo \& G. A. Davis (Eds.), Handbook of gifted education (3rd ed.) (pp. 45-59), Boston: Pearson Education.

Ushakov, D. V. (2010). Olympics of the mind as a method to identify giftedness: Soviet and Russian experience. Learning and Individual Differences, 20, 337-344.

Wilson, M.S. \& Reschly, D.J. (1996). Assessment in school psychology training and practice. School Psychology Review, 25, 9-23.

Wechsler, D. (1974). Wechsler intelligence scale for children-Revised edition. San Antonio, TX: The Psychological Corporation.

Wortham, S. C. (2005). Assessment in early childhood education (4th ed.). Upper Saddle River, NJ: Pearson. 